\title{
EDITORIAL
}

\section{DRUG RESISTANCE IN VISCERAL LEISHMANIASIS}

Visceral Leishmaniasis (VL) or kala-a-zar is endemic in Bangladesh. Historically VL was first described in 1824 , in Jessore district of the then Bengal now Bangladesh. ${ }^{1}$ A gradual spread thereafter the disease embraced gradually almost the entire subcontinent. In 1903 Donovan in Madras and Leishman in London independently identified the parasite from the splenic tissues in autopsies of patients who died from VL ${ }^{2}$ and it was Ronald Ross who proposed the name Leishmania donovani for the newly found parasite. ${ }^{2}$

Since long the treatment of choice for VL, has been pentavalent antimony which was discovered a century ago. Trivalent antimony was also used with similar outcome. Of Pentavalent antimonials Urea stibamine and sodium stibogluconate ( $\mathrm{Sb}$ ) was the most widely used and reliable. But these well known drugs is gradually loosing its long time reputation due to the various side effects, its duration and method of treatment, the cumbersome procedure of prolonged hospitalization and the recent reports of drug resistance developed by the parasite in different regions. Reports have shown a staggering $65 \%$ resistance in Northern Bihar of India and are pacing up in other regions of India as well. ${ }^{3}$. The drug next on the list is Amphotericin B, which in spite of being quite efficacious has serious side effects and quite expensive. The expense part is also true for other alternative drugs such as liposomal Amphotericin B, Miltefosine etc. while drugs like paromomycin is not available. Reports regarding resistance to Miltefosine have also been found in a recent study in Bangladesh which is yet to be published (personal communication).

The reason for resistance of the parasite to $\mathrm{Sb}(\mathrm{V})$ has been a major concern among the researchers in the subcontinent. Inadequate treatment, premature termination of treatment and immunologic or pharmacokinetic defects has all been proposed as the cause. It has been observed that the gene that is responsible for drug resistance is present in the parasite at a low level and amplification occur post exposure to the drug. Resistance has been seen to occur with in 5 to 50 generations after first exposure to the drug with a major cause behind the process being suboptimal exposure to the said drug leading to survival of the strain giving ample time to acquire resistance. $^{4}$

The initial observation that drug resistance is developing against $\mathrm{Sb}(\mathrm{V})$ was in Bihar, India between the periods 1977 to $1981^{5}$ which led to the modification of the dosage schedule of the drug from $10 \mathrm{mg} / \mathrm{kg}$ to $20 \mathrm{mg} / \mathrm{kg}$ and from 6 to 10 days course to a 20 to 40 days course by the World Health Organization. Over the years the efficacy of the drug declined with an initial response of $97 \%$ cure of patients on a 40 days course in-comparison to a $81 \%$ response to a 20 day course $^{6}$ to only $60 \%$ cure rate with a $20 \mathrm{mg} / \mathrm{kg}$ dose in Bihar, India. ${ }^{7}$ The resistance of VL to antimony compounds has also been found in other geographical locations as well and the measure to overcome the situation by increasing the dose has been back fired by the serious side effects of the drug leading to sudden deaths.

The social reason underlined behind the development of drug resistance in Bihar India, a hyper endemic zone for kala azar prevails quite similarly in Bangladesh which includes discontinuation of treatment on part of the patient, different dosage schedules and methods of administration adapted by the physicians and presence of substandard drugs in the market without a proper monitoring system regarding the indiscriminate use and selling of the drugs in the endemic areas.

Alternate therapy with amphotericin B has shown some promising results in Bangladesh and India alike. The cure rate was $>97 \%$ at doses of $0.75 \mathrm{mg} / \mathrm{kg}$ for 15 infusions on alternate days. Side effects such as infusion reaction and thrombophlebitis are universal along with occasional hypokalaemia, thrombocytopenia, myocarditis and death. Nephrotoxicity is extremely rare. ${ }^{8}$ Though relapses might occur but patients have been successfully retreated with the same drug. ${ }^{8}$ The extremely high cost of the safe and efficacious Liposomal Amphotericin B has made its use impractical in the kalaazar endemic regions. Thus amphotericin B may be a promising drug either alone or in combination provided proper trials conducted in Bangladesh. 
Miltefosine an effective substitute for $\mathrm{Sb}(\mathrm{V})$ is gradually making its way in the treatment formulation of Kala azar. At a dose of $100 \mathrm{mg}$ daily for patients weighing $\geq 25 \mathrm{~kg}$ and $50 \mathrm{mg}$ for those $<25 \mathrm{~kg}$ orally for 4 weeks with a cure rate of $95 \%$ and minimal side effects apart from its teratogenicity, was thought to be an affordable and acceptable solution to the ongoing problem faced with $\mathrm{Sb}(\mathrm{V})$. But unfortunately reports regarding treatment failure with Miltefosine from different parts of India and Bangladesh have become a major concern.

Paramomycin, an amino glycoside is yet to be investigated thoroughly though it showed glimpses of hope to the researchers with $93 \%$ cure rate in one study ${ }^{9}$ in India but unfortunately the manufacturers of the drug discontinued its production.

Ketoconazole an orally administrable anti fungal drug has also been tried in the treatment of kala azar. In one study in Bangladesh 4 out of 16 cases achieved parasitological cure and 12 cases achieved clinical cure $^{10}$. While another study in India 4 of 5 cases responded to the drug ${ }^{11}$. The researchers from Bangladesh had at that time suggested a large scale clinical study with this drug especially in those who showed resistance to $\mathrm{Sb}(\mathrm{V})$.

Researchers like Shyam Sundar, TK Jha and CP Thakur have been working relentlessly to find out the pattern of drug resistance in Indian Kala azar and an effective drug and dosage schedule to combat the situation. Measures may be taken to develop multi drug therapy for VL treatment which may show results like we have seen in tuberculosis and leprosy.

\section{H.A.M. Nazmul Ahasan}

Professor of Medicine, Dhaka Medical College, Dhaka.

\section{References:}

1. Sengupta PC. History of kala-azar in India. Indian Med Gaz 1947; 82: 281-6.
2. Bern C,Chowdhury R.The epidemiology of visceral leismaniasis in Bangladesh:prospects for improved control. Indian Med J Res 2006; 123:275-88.

3. Sundar S. Drug resistance in Indian visceral leishmaniasis. Trop Med Int Health 2001; 6: 84954 .

4. Haimeur A, Ouellette M. Gene amplification in Leishmania tarentolae selected for resistance to sodium stibogluconate. Antimicrob Agents Chemother 1998; 42: 1689-94.

5. Thakur CP, Kumar M, Singh SK et al. Comparison of regimens of treatment with sodium stibogluconate in kala-azar. Br Med J (Clin Res Ed) 1984; 288:89597.

6. Thakur CP, Kumar M, Kumar P, Mishra BN \& Pandey AK. Rationalisation of regimens of treatment of kala-azar with sodium stibogluconate in India: a randomized study. British Medical Journal 26, 21-25.

7. Sundar S, Rosenkaimer F, Murray HW. Immunochemotherapy for a systemic intracellular infection: accelerated response using interferon-c in visceral leishmaniasis. Journal of Infectious Diseases 171, 992-996.

8. Mishra M, Biswas UK, Jha AM, Khan AB. Amphotericin vs. sodium stibogluconate in ${ }^{\circledR}$ rst-line treatment of Indian kala-azar. Lancet 1994; 344: 1599-1600.

9. Jha TK, Olliaro P, Thakur CP et al. Randomized controlled trial of aminosidine (paromomycin) $\mathrm{v}$ sodium stibogluconate for treating visceral leishmaniasis in North Bihar, India. British Medical Journal 1998; 316: 1200-1205.

10. Nazmul Ahasan HAM, Rafiqueuddin AKM, Azhar MA, Chowdhury MAJ. Ketoconazole in the treatment of visceral leishmaniansis (kala-azar). Trop Doct 1996; 26: 197-98.

11. Wall JI, Aggrawal P, Gupta V, Saluja S, Singh S. Ketoconazole in treatment of Visceral Leishmaniasis. Lancet 1990; 336: 810-11. 